\title{
Escenarios del descubrimiento extraterrestre: los discursos de la ciencia de la conquista en ficciones audiovisuales recientes
}

\author{
SCENARIOS OF EXTRATERRESTRIAL DISCOVERY: DISCOURSES OF THE SCIENCE \\ OF CONQUEST IN RECENT AUDIOVISUAL FICTIONS
}

\section{CENÁRIOS DO DESCOBRIMENTO EXTRATERRESTRE: OS DISCURSOS DA CIÊNCIA DA CONQUISTA EM FICÇÕES AUDIOVISUAIS RECENTES}

\author{
Cristian Foerster $* 1$ \\ crfoersterm@gmail.com
}

\begin{abstract}
Resumen
En 2002, Elon Musk funda SpaceX, compañía cuya misión es mandar el primer cohete tripulado a Marte. Catorce años después, National Geographic estrena Mars, serie que alterna entre el documental y la ciencia ficción dura para preguntarse por los problemas que tendrían que sobrellevar los primeros colonos terrícolas en su travesía marciana, a la vez, que expone los progresos de la humanidad para alcanzar esta meta. Consecuentemente-y desde la perspectiva de las humanidades (la historia de la ciencia particularmente)-en este artículo analizaré las tensiones narrativas que envuelven al escenario fundacional sobre el que se articula la inminente empresa de colonización de Marte. De acuerdo con Diana Taylor y Juan Pimentel, desmenuzaré cómo, a través de la administración de la idea de fascinación, la ciencia y los científicos se transformaron en los protagonistas en el escenario del descubrimiento y conquista de nuevos territorios. Simultáneamente-y en diálogo con Cara a cara con el planeta, de Latour-inscribiré los conflictos que supone la conquista marciana en una genealogía que la emparenta con las figuraciones de los viajes antárticos de la primera modernidad y la colonización de América. Desde el espejo antártico, este texto predice el destino de la ilusión marciana.
\end{abstract}

Palabras clave: ciencia de la conquista, escenario del descubrimiento, performatividad, fascinación

\section{Abstract}

In 2002, Elon Musk founds SpaceX, a company whose mission is to send the first

$1 *$ Facultad de Letras de la Pontificia Universidad Católica de Chile

Tekoporá ${ }^{\circledR}$. Centro Universitario de la Región Este. Universidad de la República (C) Forester. (2021)

Este es un artículo de Acceso Abierto distribuido bajo licencia Creative Commons (CC BY NC 4.0) 
manned rocket to Mars. Fourteen years later, National Geographic launches Mars, a series that alternates between documentary and hard science fiction to wonder about the problems that the first earthly settlers would have to overcome on their Martian journey, at the same time that it shows humanity's progress in the achievement of this goal. Consequently-and from the perspective of the humanities (the history of science in particular)—in this article, I will analyze the narrative tensions that surround the founding scenario on which the imminent corporate colonization of Mars is articulated. Following Diana Taylor and Juan Pimentel, I will break down how, through the administration of the idea of fascination, science and scientists have become the protagonists of the scene of the discovery and conquest of new territories. Simultaneously-and in dialogue with Face to Gaia, by Latour-I will inscribe the conflicts that the Martian conquest supposes in a genealogy that relates it to the figurations of the Antarctic travels of the first modernity and the colonization of America. From the Antarctic mirror, this text predicts the fate of the Martian illusion.

Keywords: science of conquest, scenarios of discovery, performativity, fascination

\section{Resumo}

2002, Elon Musk funda SpaceX, companhia cuja missão é mandar o primeiro foguete tripulado a Marte. Quatorze anos depois, National Geographic estreia Mars, série que alterna entre o documentário e a ciência ficção dura para questionar os problemas que teriam que enfrentar os primeiros colonos terráqueos na sua travessia marciana, ao mesmo tempo que expõe os progressos da humanidade para alcançar essa meta. Consequentemente - e desde a perspectiva das humanidades (a história da ciência particularmente) -, neste artigo são analisadas as tensões narrativas que envolvem $o$ cenário fundacional sobre o que se articula a iminente empresa de colonização de Marte. De acordo com Diana Taylor e Juan Pimentel, será esmiuçado como, através da administração da ideia de fascinação, a ciência e os científicos se transformaram nos protagonistas no cenário do descobrimento e conquista de novos territórios. Simultaneamente - e em diálogo com Cara a cara con el planeta, de Latour- se inscrevem os conflitos que supõem a conquista marciana em uma genealogia que a emparenta com as figurações das viagens antárticas da primeira modernidade e a colonização de América. Desde o espelho antártico, este texto prediz o destino da ilusão marciana.

Palavras-chave: ciência da conquista, cenário do descobrimento, performatividade, fascinação 


\section{Viajar al espacio en tiempos de pandemia}

El 30 de mayo del 2020, en medio de la pandemia de Covid-19 que tenía a prácticamente todos los países del mundo en cuarentena, despegó desde Cabo Cañaveral rumbo a la Estación Espacial Internacional (EEI) el cohete Falcon 9, transportando consigo la cápsula Dragon 2 o Crew Dragon, que llevaba en su interior a los astronautas de la NASA, Bob Behnken y Doug Hurley. Este evento poseía, según las autoridades norteamericanas, un carácter histórico, no solo por ser el primer lanzamiento realizado desde estas tierras luego de nueve años, o que fuera la primera misión mixta entre la NASA y el sector privado de este país, sino, como señalaron Mike Pence y Donald Trump en sus discursos ${ }^{2}$, como el hito que volvía a posicionar a los Estados Unidos como líder indiscutible en la conquista del espacio. Mientras se transmitía en vivo este espectáculo científico, tecnológico y político, en distintas ciudades del país se desarrollaban protestas por el asesinato de George Floyd. Trump se refirió a estos hechos como lamentables y que eran organizados por grupos de extrema izquierda para conducir a América a la anarquía, manchando la imagen del fallecido. Estos, además, según el presidente, empañaban la importancia e impacto de este acontecimiento, que debía embargar a toda la población en un sentimiento de orgullo patrio; mismo sentimiento de supremacía que había llevado al hombre a la Luna, pero por sobre todo, articulado los valores y principios de esta nación.

Uno de los actores principales de este evento fue SpaceX, empresa privada fundada y dirigida por Elon Musk el 2002, y cuya meta principal es la colonización del planeta Marte por medio de la construcción de cohetes reutilizables, entre otras innovaciones tecnológicas. Esta compañía contratada por la NASA para esta misión también es una de las protagonistas de la serie Mars (2016) de National Geographic Channel. Esta serie, que consta hasta el momento de dos temporadas, alterna entre el documental y la ciencia ficción dura ${ }^{3}$ para narrar, por un lado, los desafíos que tienen que encarar los primeros colonizadores marcianos en los años 2033 y 2037, y por otro, los actuales avances técnicos y científicos que harían esto posible. Mars, a pesar de la presunta objetividad del género documental, posee una evidente dimensión propagandística a favor de la conquista de Marte y de la agencia aeronáutica norteamericana. Para articular este discurso, la serie enarbola un relato enmarcado en una visión positivista de la ciencia, a la vez que establece distintos paralelismos históricos para la justificación de dicha empresa. Hay dos paralelismos que plantea la serie, que a mi juicio, son sumamente interesantes de analizar de manera crítica, tanto desde una perspectiva historiográfica como performativa: la conquista y/o descubrimiento del continente americano por Colón-referencia que solo es soslayada en un capítulo, pero cuya presencia determina gran parte del sentido que le otorga la serie a la colonización de Marte-y la conquista y domesticación de la Antártida durante el siglo XX y XXI.

\footnotetext{
${ }^{2}$ Se puede ver completa la transmisión en vivo en el siguiente link: https://www.youtube.com/watch?v=v4d-Q7FINnA\&t=20914s. Desde 5:20:00, comienza el discurso de la presidencia.

${ }^{3}$ A diferencia de la ciencia ficción tradicional, este subgénero le concede una mayor importancia a los detalles técnicos y científicos en la narración.
} 
Por estas características, para estructurar este artículo exploratorio he optado emplear la serie Mars como guía y punto de partida de una reflexión más amplia sobre algunas tensiones narrativas que envuelven la inminente colonización de Marte. Para ello, enfocaré las siguientes secciones en analizar los vínculos que plantea la serie a través de dos nociones: la de "escenario del descubrimiento" (Taylor, 2017) y la de "ciencia de la conquista" (Pimentel, 2000) ${ }^{4}$, o también

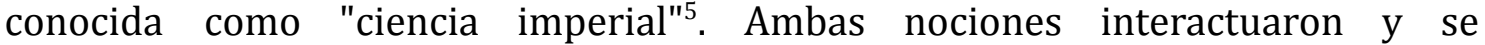
complementaron entre si a la hora de la conquista y colonización de los territorios americanos, antárticos, y ahora, en un futuro no muy lejano, del planeta Marte. Por lo mismo, es que estimo como urgente entender las implicancias tras esta nueva empresa colonial, cómo un episodio más de la guerra entre terrícolas y modernos planteada por Bruno Latour en Cara a cara con el planeta (2015).

Para la organización de este artículo, me enfocaré en un solo aspecto de la tesis de Latour $(2015)^{6}$, donde él retoma la noción de nomos de Karl Schmitt, indicando que:

Mientras los Humanos (léase modernos) son definidos como aquellos que toman la Tierra, los Terrestres son tomados por ella. En los dos casos, la Tierra sigue siendo la Madre de sus derechos, pero no es la misma madre, no es el mismo derecho y, por lo tanto, no son los mismos humanos: ya no son extraídos de la misma gleba, hechos del mismo humus, sacados del mismo compost, en una palabra no tienen la misma composición (p. 279).

Esta diferencia de composición entre terrestres y modernos se traduce en dos maneras radicalmente divergentes de relación con el entorno, que podemos caracterizar, de forma simplificada, como: los que ejercen una soberanía sin conciencia de las condiciones geofísicas y socioambientales del entorno (modernos); y los que asumen estas condiciones y se hacen cargo de su preservación (terrestres). Es por culpa de esta incompatibilidad en las prácticas y creencias respecto a los modos de vincularse con un mismo territorio planetario es que cuando estos pueblos entran en contacto, se provoca una guerra ${ }^{7}$, muchas veces no declarada. Así, para aclarar estos conflictos silenciosos y silenciados, es que estudiaremos la evolución histórica de la performatividad de uno de los miembros principales del pueblo moderno: los científicos y su ingreso como protagonistas al escenario del descubrimiento.

\footnotetext{
${ }^{4}$ Este término nunca es empleado explícitamente por Pimentel, sin embargo, a mi parecer, sintetiza la tesis de su artículo The Iberian Visión: Science and Empire in the Framework of the Universal Monarchy 1500-1800. Publicado en The University of Chicago Press on behalf of The History of Science Society Stable, 2000.

${ }^{5}$ Véase la página 10 del artículo de Carlos Madrid Casado España y la Revolución Científica: estado de la cuestión de una polémica secular.

${ }^{6}$ Para un análisis crítico más detallado del argumento de Latour véase "Humanos y terrícolas en la guerra de Gaia", capítulo del libro ¿Hay un mundo por venir? Ensayo sobre los miedos y los fines (Buenos Aires/Argentina, 2019) de Déborah Danowski y Eduardo Viveiros de Castro.

${ }^{7}$ También es importante tener presente que para Schmitt la política es simplemente una extensión de la guerra.
} 
Para finalizar esta introducción, considero pertinente especificar un poco más lo que entenderemos por la performatividad de la ciencia, es decir, la serie de prácticas y costumbres que garantizan, siguiendo esta vez a Isabelle Stengers, la "cientificidad" de la ciencia. Ella en Otra ciencia es posible. Manifiesto por una desaceleración de las ciencias (2019) plantea-a grandes rasgos-un desfase y/o tensión entre el dominio público de los saberes respectivos a la ciencia y la práctica científica. 0 expresado en otras palabras, lo que concierne a un científico en su laboratorio no es lo mismo que preocupa a los ciudadanos sobre sus investigaciones $^{8}$. No obstante, a pesar de este desfase, la opinión pública le sigue exigiendo a la ciencia la respuesta de todo tipo de problemas, que muchas veces sobrepasan los campos disciplinares de sus actores, por ese lugar ganado por la racionalidad moderna, y de la que ellos exclusivamente detentan. Asimismo, la exclusividad del conocimiento científico supone, para garantizar su poderío, una administración de la idea de fascinación que reviste a sus avances $y$ descubrimientos, a través de la organización de una suerte de culto sobre las zonas ocultas y/o difíciles de comprender de su labor para el público general. Esta perspectiva que asume este artículo, sin embargo, cabe precisar, no desea contribuir al discurso difamatorio contra la ciencia como una práctica deshonesta, sino más bien a establecer un diálogo crítico desde las humanidades, resaltando los distintos aspectos performativos de los científicos que contribuyeron a generar esta visión negativa ${ }^{9}$.

Las siguientes tres secciones tratarán sobre: la noción de fascinación, su vínculo con la ciencia de la conquista y llegada del humano a la Luna; la configuración del escenario del descubrimiento y el sitio que ocupaba en él la ciencia y los científicos; el escenario antártico y la modernización de la ciencia de la conquista como una antesala para la colonización de Marte.

\section{Ciencia y conquista: The Crown y los límites de la fascinación}

Es curioso que todas las personas con que he conversado sobre esta investigación me hayan respondido casi siempre lo mismo: que les parecía fascinante. El entusiasmo contenido en esta palabra, sin embargo, no creo responda a una supuesta originalidad de esta temática ni a mi propuesta para cómo abordarla. A mi parecer, esta exclamación más bien se debe a que la idea misma de descubrir nuevos territorios, y su posterior conquista, se encuentra íntimamente ligada a la fascinación. Para Pascal Quignard ${ }^{10}$ la fascinación nos remite en primera instancia a la fijeza de la mirada del cazador sobre su presa y cómo esta queda paralizada/hechizada por ese flechazo visual que antecede la trayectoria e impacto de la flecha real. Este instante de parálisis entre el cazador y

\footnotetext{
${ }^{8}$ Es el caso de las Organismos Genéticamente Modificados (OGM) que analiza Stengers en las primeras páginas de su libro.

${ }^{9}$ Quizás el mayor teórico de esta visión crítica de la ciencia/técnica moderna sea Martin Heidegger. Para más detalles véase Heidegger: existir en la era técnica (UDP 2014) de Jorge Acevedo Guerra

${ }^{10}$ Esta idea fascinación es clave para Quignard y aparece mencionada de manera dispersa en varios de sus libros, como por ejemplo, El origen de la danza (interZona editora 2017) o Retórica Especulativa (El cuenco de plata 2006), entre otros.
} 
su presa es el origen de la fascinación y la base para entender, siguiendo a Quignard, sus múltiples derivaciones: la poesía, la infancia, los cultos fálicos, el fascismo, y agregaría yo a esta lista, la ciencia de la conquista.

Esta última noción es acuñada por el historiador Juan Pimentel como una estrategia narrativa para argumentar que en España sí existió un desarrollo científico entre los años 1500 y 1800, en contraposición a la Leyenda Negra-la inexistencia de avances científicos-que recubre a este país, luego de la instalación del relato universalista de la Revolución Científica ${ }^{11}$. Pimentel arguye que España fue una pionera en este tipo de ciencia imperial, que engloba a la cartografía, la cosmología, la navegación y la construcción de distintos aparatos burocráticos, como fueron la Casa de la Contratación y el Consejo de Indias, entre otras. Estos avances, no obstante, fueron posteriormente despreciados y criticados por su enfoque utilitario y pragmático, pues solo habrían estado al servicio de la organización del imperio español, a diferencia de los de la ciencia moderna, cuyos fines y aportes serían universales y siempre positivos.

En los distintos tratados sobre este tipo de ciencia habitualmente la encontramos asociada a la caza ${ }^{12}$, práctica cultivada por las órdenes de caballería. Esta ligazón tenía como fin volver familiar estos avances y justificar e incentivar las empresas de conquista en el territorio americano, entendiendo a ésta como una prolongación de este tipo de prácticas. De este modo, el lazo entre cacería y ciencia de la conquista adquiere un nuevo espesor si lo entendemos como una transmutación más en la trayectoria trazada por el sentimiento de fascinación. Un ejemplo reciente de esta historia lo podemos encontrar representado en el capítulo "Polvo lunar" de la serie The Crown (2016). En él se nos muestra al príncipe Felipe de Edimburgo sufriendo una crisis psicológica al no poder aceptar su vejez, al mismo tiempo que fascinado con los astronautas que llegaron a la Luna. Esta hazaña tecnológica es leída inconscientemente por él bajo los códigos de las órdenes de caballería, transformando en héroes cuasi míticos al comandante Neil Armstrong y los pilotos Edwin F. Aldrin y Michael Collins. Sin embargo, en la conversación que mantienen los cuatro en los aposentos del Palacio de Buckingham, Felipe se decepciona, al comprender que los miembros del Apolo 11 no responden a sus expectativas heroicas. Ellos, más que conquistadores de nuevos territorios tipo Colón, se comportan como funcionarios de la ciencia que los movilizó fuera del planeta, siendo incapaces, por las labores técnicas y científicas que debían cumplir, de maravillarse con el paisaje inédito en el que estaban inmersos, así como de comprender las significancias-estéticas, filosóficas, científicas, etc.-de esta proeza.

\footnotetext{
11 Para saber más de esta noción revisar el capítulo 10 ("The place of scientific revolution in the history of Western Civilization") del libro The origins of modern science 1300-1800 (1957).

${ }^{12}$ Véase p.35 del artículo "Spain and the Scientific Revolution: Historiographical Questions and Conjetures" de Victor Navarro y William Eamon, presente en el libro Más allá de la Leyenda Negra: España y la Revolución Científica (2007).
} 
Lo interesante de la escena anterior es que representa claramente como el aura de fascinación que reviste a la ciencia de la conquista-y que posibilita los viajes de descubrimiento-permanece vigente hasta nuestros días, actualizada bajo la modalidad de la empresa espacial. Esta actualización consistiría, entre otros aspectos, en recuperar un escenario del descubrimiento y la performatividad de los conquistadores. Esta operatoria performativa, es la que vemos en acción cuando Aldrin implanta la bandera de los Estados Unidos en la Luna y la saluda, repitiendo el mismo gesto inaugural de Colón al pisar el continente americano en 1492.

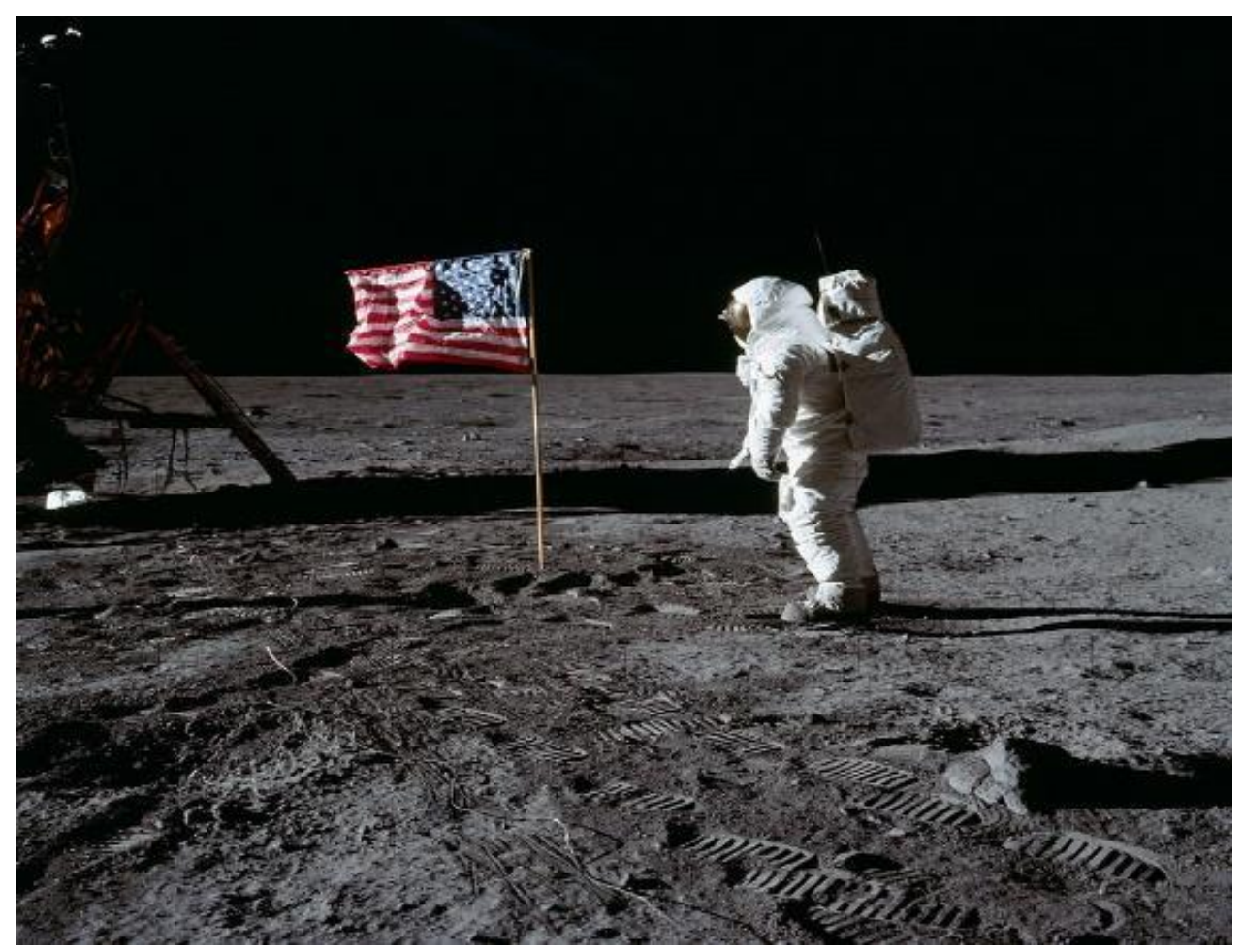

Figura 1. Buzz Aldrin y la bandera de EE.UU en la Luna. Fotografía tomada por Neil Armstrong en 1969. Encontrada en Wikipedia en el apartado sobre la misión Apolo 11. La imagen es de dominio público y pertenece al archivo de la NASA.

\section{Escenarios fascinantes}

Para que la inminente conquista y colonización de Marte, planteada por Mars, sea factible en el año 2037, es necesario revivir y actualizar las prácticas propias de un escenario del descubrimiento y la fascinación que este nos provoca, volviéndoles a dar sentido, pues solo así sus actores-científicos e ingenieros en este caso-podrán desplegar a cabalidad la performatividad necesaria para sostener esta empresa en el tiempo. En otras palabras, el proceso de colonización de un territorio inédito como Marte o América, no solo requiere de la existencia de distintos avances científicos y técnicos que lo posibiliten, y de una voluntad política y económica que lo respalde, sino también de una performatividad, es decir de la puesta en escena de distintas prácticas y gestualidades heredadas, que garanticen y convenzan al público de su importancia y sentido. 
Diana Taylor, en El archivo y el repertorio (2017), nos advierte que este tipo de escenario "activa lo nuevo al evocar lo viejo, las muchas otras versiones del escenario del descubrimiento que lo dotan de poder afectivo y explicatorio" (p.100). Así, una de sus funciones sería adormecernos con la sensación de familiaridad que nos proveen sus evocaciones, ocluyendo las atrocidades que en él se cometen. Por lo mismo, el escenario del descubrimiento, como sistema de visibilidad paradigmático, también asegura la invisibilidad de ciertos agentes -los espectadores no autorizados- que para el caso de la conquista de América, siguiendo a Taylor, serían los indígenas. La presencia y agencia del indígena habría sido invisibilizada en este contexto, al ser presentada-tanto por los conquistadores como por los testigos de la performance de la conquista-como un "recipiente vacío", sin alma; como seres más parecidos a los animales que a los humanos, como señala Colón en sus cartas, y por ende como parte consustancial de un paisaje natural dispuesto a ser descubierto, conquistado y explotado.

En este punto, me parece productivo complementar la argumentación de Taylor, expandiendo aún más su metáfora teatral y señalar que, para el funcionamiento adecuado del escenario del descubrimiento se requiere, al igual

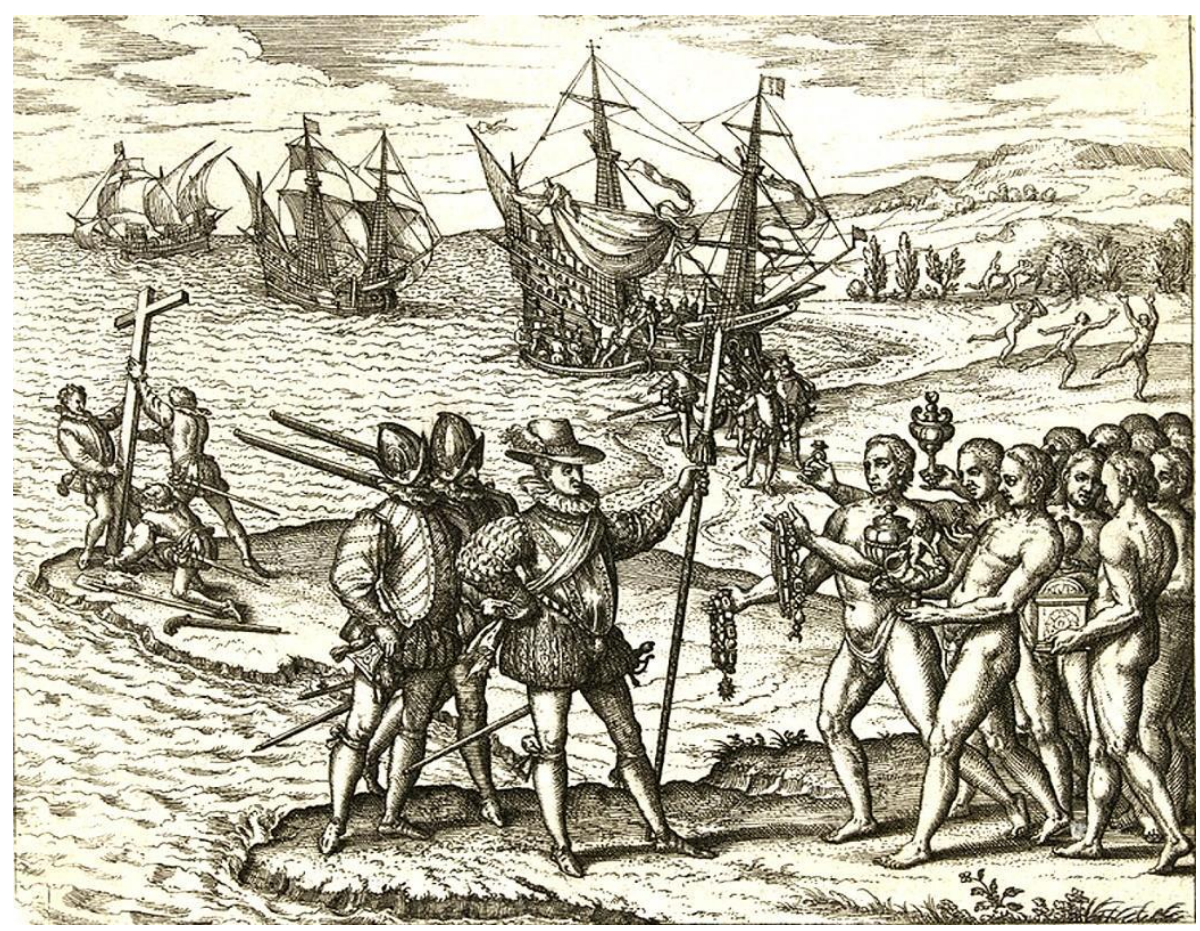

Figura 2. "Colón cuando llegó a la India por primera vez...". Grabado de Theodor de Bry (Frankfort, 1594).

que para un teatro moderno, una diversidad de asistentes técnicos y tramoyas tras bambalinas, que aseguren y velen por la efectividad performativa de lo exhibido en escena. Uno de estos agentes tras bambalinas serían los distintos actores que participan, desarrollan e implementan la ciencia de la conquista en América. De este modo, el escenario donde tiene lugar la performance del descubridor es cimentado, entre otros elementos, por un aparataje científico y técnico, y también 
artístico, que administra e inocula fascinación a la escena. Este tipo de relación también queda patente en el grabado de Theodor de Bry que analiza Taylor. En él podemos ver como las tres carabelas ocupan la parte superior izquierda de la imagen, formando una franja horizontal que apoya la disposición que ocupan Colón y sus compañeros en la parte inferior izquierda. La presencia de las naves no solo le confiere a la imagen un equilibrio interno, sino que entendemos, a partir de su perspectiva, que de ellas descendieron los descubridores. De esto, podemos inferir que solo es posible para Colón desplegar su performance en este escenario gracias a la agencia ${ }^{13}$ de las carabelas $^{14}$, y por ende, de los distintos conocimientos involucrados en su factura y conducción.

La performance del descubridor, a su vez, consistía en plantar la bandera del imperio y/o nación a la que servía, junto a la proclamación de discursos que reclamaban derecho y soberanía sobre el territorio en cuestión. Los testigos de esta escena, autorizados o no, le otorgaban al descubridor la legitimidad necesaria para transformar ese acto en ley, o en términos de Taylor, el ingreso al ámbito codificado del archivo de un repertorio determinado de prácticas y saberes, que luego serían actualizados durante toda la colonización del Nuevo Mundo. De este modo, todo escenario del descubrimiento supone volver a revivir, a través de la performance, los distintos aspectos simbólicos, políticos y sociales involucrados en esa escena fundacional y lo que allí tuvo lugar: el encuentro entre dos mundos, uno descubierto y el otro por descubrir.

En la actualidad la noción de descubrimiento la asociamos habitualmente al terreno allanado por la ciencia moderna; a las innovaciones y hallazgos obtenidos en laboratorios por medio del método científico. No obstante, la idea misma del descubrimiento, tiene su origen en el contacto entre esos dos mundos, en ese escenario donde tanto científicos como sus desarrollos técnicos ocupaban, ya sea un lugar secundario-como las carabelas en el grabado de de Bry-o completamente al margen de la visibilidad del conquistador, como es el caso de Francisco Hernandez de Toledo $^{15}$, científico español cuya obra sobre el Nuevo Mundo fue escasamente difundida y conocida, a pesar de haber sido encargada directamente por Felipe II. Con la aparición del relato de la Revolución Científica, la ciencia de la conquista o imperial es expulsada del territorio científico, sin embargo, siguió conservando como su horizonte de sentido la noción de descubrimiento. De algún modo, durante los siglos venideros, ocurrió una transformación al interior del escenario del descubrimiento, donde ya no era el conquistador quien debía ocupar el rol protagónico sino el explorador, figura edulcorada por el aura de la ciencia moderna, pero que continuó acarreando

13 Cuando empleo este término me refiero a que "un "ser vivo" es un agente que vive con otros seres vivos como ser vivo, y con el cual interactúan otros seres vivos como seres vivos." (Lestel, 2018, p.20). Esta concepción apunta a superar una comprensión exclusivamente biológica de la vida.

${ }^{14}$ La presencia de las Carabelas es recurrente en la iconografía de la época. Por ejemplo la podemos rastrear en el Regimiento de Navegación (Madrid, 1606) de Andrés García de Céspedes, así como en el Instauratio Magna (Londres, 1620) de Francis Bacon.

${ }^{15}$ Para un estudio mayor de la figura de Hernandez véase el libro de José María Lopez Piñero y José Pardo Nuevos materiales y noticias sobre la Historia de las Plantas de Nueva España de Francisco Hernandez (Valencia 1994). 
consigo toda la performatividad de sus antecesores.

Otro agente clave para la operatividad del escenario del descubrimiento es la presencia de textos que promuevan, justifiquen y divulguen el valor de este tipo de empresas. Es decir, de promotores, que no necesariamente participan de manera directa en este escenario, pero que son capaces de todos modos de transmitir en sus narraciones, a través de los relatos y comentarios de los descubridores, lo que está ocurriendo en el Nuevo Mundo. Un personaje paradigmático que cumplió este rol fue Pedro Mártir de Angleria, humanista italiano que sirvió en la corte de los Reyes Católicos y escribió las Décadas de Orbe Novo, obra que cuenta distintos eventos que tuvieron lugar en América, así como las características y particularidades del territorio y sus pobladores. Esta función secundaria para las lógicas del escenario del descubrimiento americano, al igual que lo ocurrido con la ciencia, se acoplará en el futuro a la performatividad del conquistador-explorador-científico, recordándonos la importancia de la opinión pública para estas empresas. En un capítulo de la segunda temporada de Mars se nos advierte que un aspecto crucial para que la continuidad del proyecto de habitar este planeta, tanto en su etapa actual de planificación y desarrollo, como en el futuro del año 2037, es contar con el respaldo de la opinión pública, para garantizar el apoyo económico de los patrocinadores, privados y/o estatales. Lo particular del escenario del descubrimiento marciano es que el rol del promotor-divulgador ya no lo cumple un actor externo a la escena, sino que son los mismos científicos-colonizadores los que deben llevar esto a cabo en una especie de reality-show ${ }^{16}$.

En esta sección, intenté explicar como ciertos roles y personajes que se encontraban tras bambalinas en el escenario del descubrimiento americano trazado por Taylor, ingresaron en él en su devenir y se fusionaron, dando paso a un nuevo tipo de actor que debía cumplir estas distintas funciones. De este modo, los exploradores científicos, hasta llegar al futuro dibujado por Mars, a pesar de su discurso de rechazo a los antiguos, continuaron repitiendo las mismas prácticas de los primeros descubridores, y por ende, reviviendo y actualizando la serie de concepciones y consecuencias materiales y simbólicas que tuvieron lugar en el pasado: la invisibilización de los distintos agentes que pueblan un territorio antes de su descubrimiento.

\section{De Marte a la Antártida: un repertorio común}

La síntesis de roles y prácticas al interior del escenario del descubrimiento, expuesta en el capítulo anterior, en tanto puesta en escena de un complejo entramado performativo, tuvo su exposición al público durante los viajes de exploración al continente antártico impulsados por el Imperio Británico a comienzos del siglo XX. Este tipo de expediciones exigieron una modernización de la ciencia de la conquista, para favorecer la organización imperial británica

\footnotetext{
${ }^{16}$ En la segunda temporada esto es representado literalmente por la estación espacial China que orbita Marte, encargada del proyecto de terraformación. Para conseguir fondos, los científicos a cargo son filmados día y noche por cámaras que transmiten en vivo sus labores a todo el mundo vía streaming.
} 
alrededor del globo. Según el historiador Edward Larson (2011), "el Imperio no solo se trataba de la conquista física de territorios; para los británicos, este fue siempre acerca de la exploración científica y la explotación sistemática de ellos, incluso cuando la definición y concepción misma de ciencia hubiera evolucionado"17 (p.13). Esta afirmación, leída en los términos de este artículo, nos remite a como, en el escenario del descubrimiento antártico, la ciencia de la conquista junto a la ciencia moderna formaron parte de un mismo proyecto imperial de conquista y dominación. Sin embargo, a diferencia de lo ocurrido con el Imperio Español, la empresa británica se encontraba revestida, tanto por el aura de fascinación de la ciencia imperial, como por el aparato discursivo y técnico de la ciencia moderna, lo que permitió solventar y sobrellevar sus potenciales críticas. Esta, a mi juicio, es una de las razones implícitas de porque los guionistas de Mars eligieron a la Antártida como el escenario terrestre más parecido a Marte ${ }^{18}$.

Por otra parte, las semejanzas entre ambos territorios abundan. La Antártida al igual que Marte son vastos desiertos helados, cuyos climas agrestes obligan a sus colonizadores a tomar medidas extremas para su subsistencia; su condición aislada también supone generar otras formas de abastecimiento energético, por medio de generadores de electricidad en base a combustibles fósiles y paneles solares; los dos territorios, por lo mismo, dependen de un constante flujo de intercambios comerciales con otros territorios para su sustentabilidad, lo que significa establecer complejas redes aeronáuticas y de navegación. Asimismo, Marte y la Antártida son espacios geopolíticos que ratifican el poderío humano sobre un entorno natural, invisibilizando las particularidades geofísicas y ambientales de sus ecosistemas, en pos del estudio científico que va de la mano de su libre explotación. Sobre este punto, no es descabellado trazar una continuidad entre este tipo de operatoria-concebir un territorio por su condición supuestamente desértica y aislada como tierra de nadie-con el gesto negacionista del descubridor ibérico para con el mundo prehispánico.

La serie, sin embargo, para la elaboración de este paralelismo solo se enfoca en dos momentos particulares de la historia antártica: en la Expedición Imperial Trans-Antártica, más conocida como la Expedición Endurance ${ }^{19}$, dirigida por Ernest Shackleton en el año 1914, y la vida en la Base McMurdo durante las primeras décadas del siglo XXI.

La primera vez que Ernest Shackleton viajó a la Antártida fue en 1902 como miembro de la tripulación del Discovery, embarcación comandada por Robert Falcon Scott. Uno de los mayores descubrimientos de esta expedición fue constatar que el territorio antártico era efectivamente un continente. Shackleton regresó cinco años después, ahora él al mando de una expedición privada. El nombre del barco en cuestión era Nimrod, cuya referencia al personaje bíblico vinculado a la construcción de la Torre de Babel-"un poderoso cazador delante del Señor" (Génesis 10:9)—nos recuerda tanto la descomunal impronta de esta empresa,

\footnotetext{
${ }^{17}$ La traducción es mía.

${ }^{18}$ Este paralelismo es el que organiza el capítulo 4 "Power" de la primera temporada.

19 También podemos oír el eco de esta expedición al interior de la empresa espacial norteamericana en el nombre elegido para el rover que viajó a Marte el 30 de julio del 2020 a tomar muestras del terreno: Perseverance.
} 
como la ligazón que existe entre fascinación, caza y ciencia de la conquista. Fue durante esta expedición que Shackleton y su pequeña tripulación, compuesta por varios científicos, atravesando la Barrera de Hielo, alcanzaron la Meseta Polar. Allí, junto a tres de sus hombres, izaron la bandera de su Majestad y luego la del Reino Unido, y tomaron posesión de la meseta en nombre del Rey Eduardo VII (Larson, 2011, p. 25). Este hecho fue consignado por el mismo Shackleton en su diario en enero de 1909. Este gesto suyo, que repite la misma performatividad de Colón, en cambio sucede en un escenario despoblado, sin esos espectadores no autorizados a quienes había que fascinar con la performance del descubrimiento. En su lugar, solo hay ventiscas y hielo. Esta ausencia de un público externo será saldada en su última expedición, la del Endurance, gracias a la presencia y agencia de la cámara de video.

La Expedición Endurance, última expedición importante de la así llamada edad heroica de la exploración de la Antártica, fue un fracaso en términos de las expectativas de Shackleton, al quedar atrapado el Endurance en el hielo del mar de Weddell antes de llegar a la bahía Vahsesin. Sin embargo, esta será recordada, no solo por ser una épica aventura de supervivencia, sino por las imágenes que se registraron de ella. Estas grabaciones constituyen un archivo visual de lo que fueron estas empresas y evidencian toda la performatividad de los exploradores. Estas imágenes paradigmáticas del fracaso y del esfuerzo humano son citadas en Mars para recordarnos lo que está en juego en la colonización de Marte: una épica que traspasa las barreras del tiempo y que se remonta al descubrimiento de América. De este modo, gracias a estas filmaciones y su circulación en distintos medios, es que ahora todos quienes las vemos, nos convertimos en espectadores -autorizados y no- de la performance del descubrimiento.

Estas imágenes en movimiento, a su vez, nos hablan de un cambio en la organización del escenario, pues sus códigos visuales pasan de ser teatrales a cinematográficos, cobrando aún más relevancia los distintos elementos que constituyen su escenografía. La presencia espectral de estos cuerpos, así como la del paisaje en blanco y negro, se vuelven parte de un mismo amasijo emocional dispuesto a ser interpretado y actualizado por otros. Por lo mismo, los habitantes actuales de la Base McMurdo -en su mayoría científicos e ingenieros- reviven en su día a día los esfuerzos físicos y mentales de todos los exploradores antárticos. Esto lo podemos constatar en una secuencia bastante divertida del documental de Werner Herzog Encuentros en el fin del mundo $(2007)^{20}$, donde se nos muestra el entrenamiento que debe cumplir el equipo de filmación para sobrevivir a las condiciones extremas de la Antártida. Éste consiste en recorrer una determinada distancia sin perderse, ayudados de una cuerda, pero ocupando un balde plástico en la cabeza, el cual emula la visibilidad y audición que tenemos al interior de una tormenta de nieve.

La vida en McMurdo expuesta por Mars es ajena a los momentos absurdos o de relajo filmados por Herzog. En su lugar, se nos muestra a los científicos bajo el mismo estrés que viven los habitantes de la base Olympus en Marte entre los años 2033 y 2042. Este estrés, a mi juicio, es propio del régimen cinematográfico

\footnotetext{
${ }^{20}$ En este documental también aparecen citadas las imágenes de la Expedición Endurance.
} 
hollywoodense instaurado por las películas de acción, donde todo elemento cotidiano queda subsumido bajo la óptica épica. 0 en otros términos, los científicos, al ingresar al escenario del descubrimiento como protagonistas, deben desempeñar el rol de héroes abocados exclusivamente a cumplir su misión, sin tiempo para el descanso ni el ocio. Esta falta de tiempo -propia de un sistema de producción capitalista- quizás sea la causante de la locura de un científico -premio Nobel de botánica- en Marte ${ }^{21}$, y no solo culpa de su genialidad mal administrada por efectos del aislamiento y el fracaso de su huerta. De este modo, los distintos roles que deben cumplir los científicos en el escenario marciano y el estrés que esto les conlleva, tiene su origen en los paralelismos históricos y la narrativa imperial que establece la serie, cuyo eco en la actualidad nos remite a los discursos de Trump y Pence.

Para finalizar esta sección, me parece importante volver a resaltar como el escenario del descubrimiento antártico funcionaría como una antesala al escenario marciano, en tanto la ciencia de la conquista, ahora revestida por la impronta de la ciencia moderna, permitió actualizar/modernizar las empresas imperiales. Esta suerte de doble tradición científica que opera en la Antártida supone una nueva forma -blanqueada por el hielo y el supuesto heroísmo desinteresado de los científicos- de administrar la fascinación que nos provocan los viajes de descubrimiento a tierras lejanas.

\section{Conclusiones: la urgencia de repensar el sentido de la ciencia en tiempos de guerra}

Si releemos los dos paralelismos históricos planteados por Mars que hemos revisado hasta ahora, podemos entrever una especie de estancamiento en el discurso científico, el cual continúa operando bajo el mismo paradigma expansivo y comprensivo inaugurado por la ciencia de la conquista durante el siglo XV para la logística imperial. A pesar de ello, la narrativa instalada durante toda su segunda temporada supone revivir el conflicto entre ciencia moderna y ciencia imperial, esta vez representado por las tensiones que se desencadenan en Marte tras la llegada de la empresa minera Lukrum. Los científicos de Olympus ven con malos ojos a los recién llegados mineros-tecnócratas por no respetar la agencia del planeta, así como los límites territoriales trazados por ellos para sus investigaciones. Este conflicto dramático, no obstante, resulta una ilusión o falacia, si es que entendemos que la ciencia -tanto moderna como de la conquistasiempre ha estado movilizada por intereses económicos y políticos, y no exclusivamente por un afán de conocimiento desinteresado como el propuesto por la Revolución Científica.

A mi juicio, el conflicto ahora es otro. Este, no se trataría en realidad de una guerra entre científicos y empresarios, sino entre terrícolas y modernos; entre los que deciden quedarse en la Tierra y los que anhelan otro mundo para seguir reproduciendo una misma historia de explotación sobre los territorios descubiertos. Esta historia, en la segunda temporada de Mars, se vuelve literal en el proyecto de terraformación de Marte, el cual consiste, a través de una serie de

\footnotetext{
${ }^{21}$ El capítulo en cuestión es el quinto de la primera temporada "Darkest Days".
} 
espejos-satélites que orbitan el planeta, reflejar la luz del sol sobre su superficie para calentarla hasta alcanzar temperaturas similares a las de la Tierra. Esto haría posible, a grandes rasgos, que el agua almacenada en las entrañas de Marte aflorara y se evapora produciendo oxígeno. Esta reproducción del ecosistema terrestre en Marte la podemos leer como una actualización a escala trans-planetaria de la guerra entre terrícolas y modernos planteada por Bruno Latour, donde ahora la performatividad y agencia de dos planetas entra en colisión, sin considerar sus múltiples y desconocidas repercusiones. Así, el proyecto de terraformar Marte nos obliga, entre otras tareas, a recordar los problemas y conflictos que conllevó reproducir materialmente la cosmovisión europea en el Nuevo Mundo, y si es que deseamos continuar por esa senda.

De este modo, el escenario del descubrimiento dibujado por Mars, a pesar de poseer nuevas e inéditas características, continúa actualizando sin cuestionarse la performatividad de los primeros descubridores. Por lo mismo, me parece urgente que repensemos el devenir de este escenario, donde la ciencia ingresó desde sus entretelones bajo la apariencia de un actor inocente. Solo así podremos imaginar un nuevo escenario con nuevos actores, donde el contacto entre dos mundos -o pueblos en términos de Latour- no vuelva a reproducir impunemente las lógicas de la conquista. Sé que esta tarea no es fácil, y que este pequeño artículo, en sus precarios medios, es apenas una titubeante invitación a navegar por la complejidad de este archivo. Por último, esta serie nos pone como latinoamericanos en la compleja situación de tener que decidir sobre qué tipo de espectadores deseamos ser, al obligarnos a comprender las implicancias que supone pactar o no, con la fascinante historia que nos presenta.

\section{Referencias}

Acevedo, J. (2014). Heidegger: existir en la era técnica. Santiago de Chile, Chile: Ediciones Universidad Diego Portales.

Danowski, D. \& Viveiros de Castro, E. (2019). ¿Hay un mundo por venir? Ensayo sobre los miedos y los fines. Buenos Aires, Argentina: Caja Negra Editora.

Keiser, H., Fairclough, Ph., Harding, D., Hobbs,J., Meditch, A., Nelson, E. (Productores) y Herzog, W. (Director). (2007). Encuentros en el fin del mundo [Documental]. Estados Unidos: Discovery Channel.

Latour, B. (2015). Cara a cara con el planeta. Una mirada sobre el cambio climático alejada de las posiciones apocalípticas. Buenos Aires, Argentina: Siglo XXI editores.

Larson, E. (2011). An Empire of Ice: Scott, Shackleton, and the Heroic Age of Antarctic Science. Estados Unidos: Yale University Press.

Lestel, D. (2018). Hacer las paces con el animal. Santiago de Chile, Chile: Ediciones Qual Quelle. 
Lopéz Piñero, J. M. \& Pardo Tomás, J. (1994). Nuevos materiales y noticias sobre la "Historia de las plantas de Nueva España" de Francisco Hernández. España, Valencia: Instituto de Estudios Documentales e Históricos sobre la Ciencia.

Morgan, P. (Productor). (2016). The Crown [serie de televisión]. Londres: Left Bank Pictures \& $\underline{\text { Sony Pictures Television. }}$

Navarro, V. \& Eamon, W. (2007). Spain and the Scienific Revolution: Historiographical Questions and Conjetures. En Navarro, Victor \& Eamon, William (Ed.) Más allá de la Leyenda Negra: España y la Revolución. (27-40). España, Valencia: Universitat de València: Consejo Superior de Investigaciones Científicas, CSIC, Instituto de Historia de la Ciencia y Documentación.

Pimentel, J. (2000). The Iberian Visión: Science and Empire in the Framework of the Universal Monarchy 1500-1800. The University of Chicago Press on behalf of The History of Science Society Stable.15. pp. 17-30.

Quignard, P. (2017). El origen de la danza. Buenos Aires, Argentina: interZona editora.

Quignard, P. (2006). Retórica especulativa. Buenos Aires, Argentina: El cuenco de plata.

Stengers, I. (2019). Otra ciencia es posible. Manifiesto por la desaceleración de las ciencias. Barcelona, España: Futuro anterior ediciones.

Taylor, D. (2017). El archivo y el repertorio. La memoria cultural performática en las Américas. Santiago, Chile:Ediciones Universidad Alberto Hurtado.

Young, B. \& Wilkes, J. (Productores). (2016). Mars [serie de televisión]. Estados Unidos: Imagine Entertainment \& RadicalMedia. 